DIW BERLIN

Discussion

Papers

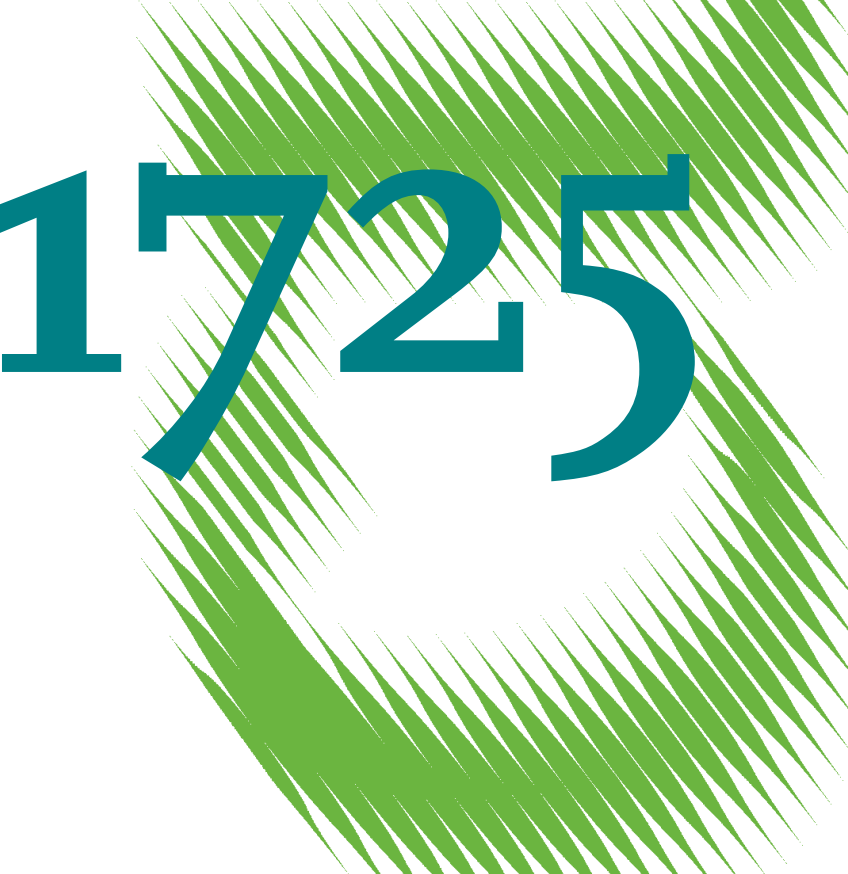

Job Search with Subjective Wage Expectations 
Opinions expressed in this paper are those of the author(s) and do not necessarily reflect views of the institute.

IMPRESSUM

(C) DIW Berlin, 2018

DIW Berlin

German Institute for Economic Research

Mohrenstr. 58

10117 Berlin

Tel. +49 (30) $89789-0$

Fax +49 (30) $89789-200$

http://www.diw.de

ISSN electronic edition 1619-4535

Papers can be downloaded free of charge from the DIW Berlin website:

http://www.diw.de/discussionpapers

Discussion Papers of DIW Berlin are indexed in RePEc and SSRN:

http://ideas.repec.org/s/diw/diwwpp.html

http://www.ssrn.com/link/DIW-Berlin-German-Inst-Econ-Res.html 


\title{
Job Search with Subjective Wage Expectations*
}

\author{
Sascha Drahs $\rangle^{\dagger}$ Luke Haywood $\ddagger$ Amelie Schiprowski ${ }^{\S}$
}

March 2, 2018

\begin{abstract}
This paper analyzes how subjective expectations about wage opportunities influence the job search decision. We match data on subjective wage expectations with administrative employment records. The data reveal that unemployed individuals over-estimate their future net re-employment wage by $10 \%$ on average. In particular, the average individual does not anticipate that wage offers decline in value with their elapsed time out of employment. How does this optimism affect job finding? We analyze this question using a structural job search framework in which subjective expectations about future wage offers are not constrained to be consistent with reality. Results show that wage optimism has highly dynamic effects: upon unemployment entry, optimism decreases job finding by about $8 \%$. This effect weakens over the unemployment spell and eventually switches sign after about 8 months of unemployment. From then onward, optimism prevents unemployed individuals from becoming discouraged and thus increases search. On average, optimism increases the duration of unemployment by about $6.5 \%$.
\end{abstract}

Keywords: Job Search, Subjective Expectations, Structural Estimation

JEL Codes: J64, D83

\footnotetext{
${ }^{*}$ The authors would like to thank Marco Caliendo, Thomas Dohmen, Peter Haan, Daniele Paserman, Johannes Schmieder, Arne Uhlendorff, Georg Weizsäcker, as well as seminar participants at Boston University, DIW Berlin, IZA, the Berlin Network of Labor Market Economists (BeNA) Summer Workshop 2015, EEA 2015, IIPF 2015, the Berlin Behavioral Economics Group (BBE) Workshop 2016, EALE 2016, and the BeNA Winter Workshop 2017, and the first CRC TRR 190 Retreat 2017 for many valuable comments. Sascha Drahs greatfully acknowledges financial support by Deutsche Forschungsgemeinschaft through CRC TRR 190.

${ }^{\dagger}$ DIW Berlin

${ }^{\ddagger}$ DIW Berlin

$\S$ IZA Bonn and DIW Berlin
} 


\section{Introduction}

Most welfare states support unemployed workers in their search for a job. This has been justified by the costs imposed by unemployment on both public finances and individuals' work careers. In particular, previous research has shown that prolonged unemployment decreases job finding prospects (Kroft et al., 2013; Eriksson and Rooth, 2014), as well as the quality of wage offers (Schmieder et al., 2016). These studies provide strong evidence that the returns to job search decrease with elapsed duration in unemployment. Less knowledge exists on how individuals perceive these returns, and how they react to their beliefs. Such knowledge is, however, important to effectively counsel and inform unemployed individuals. Given the wide use of counseling in modern welfare states, it is crucial to take into account beliefs held by unemployed individuals, and to understand how these beliefs affect job search behavior.

In this paper, we focus on the expectations held by newly unemployed job seekers about their wage prospects. We show descriptively that the average job seeker over-estimates her future wage outcome. We then use a structural dynamic job search model to analyze how this "wage optimism" affects the decision to search for work at different stages of the unemployment spell.

The data on subjective wage expectations stem from the 'Linked IZA/IAB Evaluation Dataset', which contains both survey data on subjective expectations and administrative records on labor market histories and outcomes. In line with previous evidence (e.g., by Schmieder et al., 2016), we observe that re-employment wages decrease over the unemployment spell, relative to prior wages. By contrast, subjective expectations do not take account of future reductions in the quality of wage offers. Rather, expectations are heavily anchored in past wages. The average gap between initial expectations and actually realized re-employment wages amounts to $10 \%$ in net terms. Even after one year out of employment, most individuals do not update their expectations. ${ }^{1}$ These patterns reveal that unemployed individuals do not recognize that they are searching in a highly dynamic environment.

To assess the consequences of wage optimism for job search, we introduce subjective wage expectations into a discrete-time non-stationary job search model. ${ }^{2}$ In the model, unemployed workers choose their optimal job search effort across their unemployment spell. We model individuals as holding potentially incorrect beliefs about both the average value of wage offers and, importantly, about the evolution of wage offers over the unemployment spell. We identify these two key parameters using the data on subjective expectations about future wages. Additionally, we model three sources of dynamics in the job search environment: first,

\footnotetext{
${ }^{1}$ Over-optimism by job seekers regarding future wages is consistent with evidence on the empirics of reservation wages by Krueger and Mueller (2016) and Koenig et al. (2016), who find that workers persistently misjudge their prospects and set their reservation wage according to their previous wage.

${ }^{2}$ The first non-stationary search models (with exogenous effort) were presented by Wolpin (1987) and Van den Berg (1990).
} 
the quality of the average wage offer can evolve over the duration out of employment. Second, search costs are allowed to change over time, capturing the phenomenon that job seekers find it increasingly difficult to generate job offers. ${ }^{3}$ Third, UI benefits are paid for a limited amount of time. After exhausting UI payments, benefits are reduced to the level of social assistance. Similar to Card et al. (2007) and DellaVigna et al. (2017), we build on a simplified version of Lentz and Tranaes (2005), by focusing on search effort instead of reservation wage dynamics and assume that every wage offer is accepted. ${ }^{4}$ We the model controls for observable heterogeneity in search costs and wage offers. We provide a range of estimates for different choices of the discount rate.

We use the estimated model parameters to simulate a hypothetical scenario in which individuals are perfectly informed about the stochastic evolution of wage offers. The simulation results show that wage optimism affects the trajectory of job search in a highly dynamic way. At first, the knowledge about falling wage prospects creates an incentive for unemployed workers to search more. As a consequence, having correct information about the labor market increases job finding by around $8 \%$ early in an unemployment spell compared to the optimistic benchmark. This effect weakens over the spell and eventually switches sign after about 8 months of unemployment. From then onward, the information about worsened wage offers discourages search and thereby decreases job finding by up to $15 \%$. Long-term unemployed individuals thus search less when they are well-informed about the wage offers they face. As most individuals exit during early stages of the unemployment spell, optimism prolongs the average unemployment duration by around 0.7 months (6.5\%). The amount of UI benefits paid to the average recipient therefore increases by 450 Euros. Average accepted wages decrease by about $1 \%$. Nevertheless, the dynamic pattern renders the overall implications of wage optimism ambiguous: optimism discourages search at early stages of the spell, while encouraging it at later stages. This qualitative pattern persists for different choices of the discount rate, while the estimated size of the initial negative effect of optimism decreases in the discount rate.

Our results contribute to the understanding of job search behavior in a dynamic setting and under potentially non-rational expectations. A growing literature analyzes job search under alternative behavioral assumptions than those made by standard models. For instance, DellaVigna and Paserman (2005) and Paserman (2008) study job search with non-exponential discounting. DellaVigna et al. (2017) introduce reference-dependent preferences into a job search model, making the case for a benefit schedule in which UI benefits decrease step-wise

\footnotetext{
${ }^{3}$ See, e.g., Kroft et al. (2013) and Eriksson and Rooth (2014) for evidence that the probability of a callback decreases over the unemployment spell.

${ }^{4}$ In line with this assumption, Schmieder et al. (2016) find that reservation wages of German job seekers are not binding, suggesting that they are not a meaningful driver of search dynamics in the context of our analysis.
} 
over the duration in unemployment. Caliendo et al. (2015) analyze job search strategies when the subjective job offer arrival rate depends on the locus of control. They find that a more internal locus of control is associated with higher job search effort. Spinnewijn (2015) shows that job seekers in the U.S. are overly optimistic regarding their job finding prospects. ${ }^{5} \mathrm{He}$ presents theoretical evidence that optimal unemployment insurance design is affected by the presence of biased beliefs. Arni and Wunsch (2014) observe a negative relationship between subjective wage expectations and the exit rate out of unemployment. Altmann et al. (2017) show that the provision of information to unemployed individuals via a brochure increases job finding among individuals with low re-employment prospects. We add to this literature by providing a first structural analysis of dynamic job search behavior under subjective wage expectations: based on our model, we trace search choices over the unemployment spell and contrast choices made by over-optimistic agents to choices made by perfectly rational agents.

The remainder of the paper is structured as follows: section 2 presents a search model with subjective expectations about the wage offer distribution. Section 3 describes the matched administrative and survey data. Section 4 provides reduced form evidence on wage expectations and outcomes. We describe the structural estimation in section 5 and present results in section 6. Section 7 concludes.

\section{Model}

We set up a discrete-time, non-stationary job search model similar to Card et al. (2007) and DellaVigna et al. $(2017)^{6}$, where job seekers choose the level of search intensity in each period of time. In a context where wage offers decline in value over the unemployment spell, non-stationarity is central to analyze how subjective wage expectations affect behavior. ${ }^{7}$ We first present a rational-expectations version of the model and then introduce the possibility of diverging subjective expectations.

In each period of time $t$, a worker is either employed at a job paying gross wage $w$, or unemployed with unemployment benefits $b_{t}$. At the beginning of each period, job seekers determine their level of search intensity $s_{t} \in[0,1]$, which directly translates into their perperiod probability of finding a job. Upon finding a job, workers remain employed for the entire future. As in Card et al. (2007) and DellaVigna et al. (2017), we focus on search effort instead of reservation wage dynamics and assume that every wage offer is accepted. ${ }^{8}$ We

\footnotetext{
${ }^{5}$ Evidence on persistent over-optimism also exists from other labor market contexts. Hoffman and Burks (2017) show that truck drivers over-estimate their (future) productivity without updating their beliefs.

${ }^{6}$ Both models are simplified versions of Lentz and Tranaes (2005).

${ }^{7}$ Non-stationarity in job search models was formalized by Wolpin (1987) and Van den Berg (1990), who present non-stationary job search models with exogenous effort.

${ }^{8}$ Schmieder et al. (2016) provide empirical evidence supporting this assumption, by showing that reservation wages of German job seekers are not binding.
} 
discuss alternative assumptions on reservation wages below.

Value functions The resulting value functions are given by:

$$
\begin{aligned}
V(w) & =\frac{1+r}{r} u(\tau(w)), \\
U_{t} & =u\left(b_{t}\right)+\frac{J_{t+1}}{1+r}, \text { and } \\
J_{t} & =\max _{s \in[0,1]} s \mathrm{E}_{F_{T}} V(w)+(1-s) U_{t}-c_{t}(s),
\end{aligned}
$$

where $u$ denotes the utility of consumption, $r$ is the time discount rate, $c_{t}$ is the strictly convex effort cost function in period $t, F_{t}$ is the wage distribution of job offer arrivals in period $t$, and $E_{F}$ designates the expectation over the wage offer distribution. The function $\tau$ denotes the tax and transfer function, such that consumption equals the net wage $\tau(w)$. In this problem, the job seeker's optimal search policy is the path $\left(s_{t}\right)_{t=1}^{\infty}$. It is determined by the first-order conditions

$$
c_{t}^{\prime}\left(s_{t}\right)=\mathrm{E}_{F_{t}} V(w)-U_{t},
$$

for $t=1, \ldots$. Assuming that the job search environment becomes stationary after $T$ time periods, we then get the stationary solution

$$
\begin{aligned}
U_{T} & =\frac{1+r}{s_{T}+r} u\left(b_{T}\right)+\frac{1}{s_{T}+r}\left[s_{T} \mathrm{E}_{F_{t}} V(w)-c_{T}\left(s_{T}\right)\right], \\
c_{T}^{\prime}\left(s_{T}\right) & =\mathrm{E}_{F_{t}} V(w)-U_{T}
\end{aligned}
$$

such that a complete solution of the model is obtained by backward induction.

Subjective Wage Expectations The proposed model of job search allows for non-stationarity in the benefit level $b_{t}$, the cost of effort $c_{t}$ and in the wage offer distribution $F_{t}$. As shown by the first-order conditions (4), the wage offer distribution enters the optimal search decision both directly through the value of finding a job today, $\mathrm{E}_{F_{t}} V(w)$, and indirectly through the value of finding a job in the future. Therefore, the perceived evolution of the wage offer distribution matters for search behavior. In what follows, we distinguish the objective (true) from the subjective wage offer distributions, the latter denoted $F_{t}^{s u b}(t=1, \ldots)$.

Definition of Wage Optimism We allow for a difference between the true wage offer distribution and its subjective counterpart. Given the widely established evidence of optimism as a behavioral trait, optimism with respect to the subjective wage offer distribution seems plausible. Wage optimism can be defined as follows: denote by $\left(F_{t}\right)_{t=1}^{\infty}$ the true sequence of 
cumulative wage offer distributions, and allow the job seeker to face the job search problem with subjective wage expectations $\left(F_{t}^{s u b}\right)_{t=1}^{\infty}$. We call a job seeker wage optimistic if $F_{t}^{s u b} \succ F_{t}$ for all $t \geq 1$ in the sense of first order stochastic dominance. Conversely, a job seeker is wage pessimistic if $F_{t}^{s u b} \prec F_{t}$ for all $t \geq 1$ holds.

However, we must emphasize that wage optimism as it is defined above is just one possible deviation between subjective and true wage offer distributions. It is, for instance, conceivable that subjective wage distributions are below the true path of wage offers for some periods and above for others.

Consequences of Wage Optimism When individuals would display wage optimism as defined above, this would change job search behavior in a predictable manner. To see the implications of wage optimism, consider the following expanded expression of the value of unemployment:

$$
U_{t}=\sum_{\eta=0}^{\infty} \frac{1}{(1+r)^{\eta}} S_{t+1, t+\eta+1} u\left(b_{t+\eta}\right)+\sum_{\eta=1}^{\infty} \frac{1}{(1+r)^{\eta}} S_{t+1, t+\eta}\left(s_{t+\eta} \mathrm{E}_{F_{t+\eta}^{s u b}} V(w)-c_{t+\eta}\left(s_{t+\eta}\right)\right)
$$

where $S_{t, t+\eta}=\left(1-s_{t}\right) \ldots\left(1-s_{t+\eta-1}\right)$. The first term on the right hand side is the expected utility stream from unemployment benefits, conditional on the job seeker's search behavior. The second term is the expected value of finding a job in the future less any future effort costs, again conditional on searching. From this equation, it becomes clear that the chosen search intensity involves a trade-off between the current and any future value of taking up employment.

Consider a marginal change in the perceived wage offer distribution, e.g., a wage increase $\phi_{W}$. The effect on the current expected value of work is $\partial \mathrm{E}_{F_{t}^{s u b}} V(w) / \partial \phi_{W}$, and the effect on the value of unemployment is

$$
\frac{\partial U_{t}}{\partial \phi_{w}}=\sum_{\eta=1}^{\infty} \frac{1}{(1+r)^{\eta}} S_{t+1, t+\eta} s_{t+\eta} \frac{\partial \mathrm{E}_{F_{t+\eta}^{s u b}} V(w)}{\partial \phi_{W}}
$$

This result can be used to derive qualitative predictions. First consider the case of wage optimism in a stationary job search model. In this case, the marginal effect of the increase in the subjectively expected wage on current and future values of employment is constant, i.e., $\partial \mathrm{E}_{F_{t}^{s u b}} V(w) / \partial \phi_{W}=\partial \mathrm{E}_{F_{t+\eta}^{s u b}} V(w) / \partial \phi_{W}$ for all $\eta=1, \ldots$. Therefore, the effect of wage optimism on today's search effort is unambiguously positive.

It is, of course, more realistic to consider a duration-dependent wage offer distribution. The effect of optimism on search behavior is then composed of changes in both current and 
future payoffs. To fix ideas, first consider the decision of how much to search at the beginning of the unemployment spell. Optimism about current wage offers increases the incentive to search. Conversely, optimism about future wage offers reduces the search incentive, as the cost of remaining unemployed is lowered. The net effect of optimism on early job search is thus theoretically ambiguous and remains an empirical question. Considering the effect of optimism at later stages of the unemployment spell, theory predicts that wage optimism increases search. The intuition is that the search environment converges towards the stationary equilibrium as unemployment progresses. As described above, wage optimism under stationarity unambiguously increases search.

The effect of wage optimism on initial job search is thus ambiguous. By contrast, theory predicts that optimistic individuals search more at later stages in the unemployment spell, towards the stationary period.

Learning and Reservation Wages Our model assumes that job seekers accept every wage offer, thereby assuming that any reservation wage is not binding. This central assumption is motivated by recent empirical evidence suggesting that reservation wages are not the main driver of search dynamics and the job finding hazard (e.g. Card et al., 2007; Krueger and Mueller, 2016; Schmieder et al., 2016). Given the popularity of job search models with reservation wages (c.f. the surveys by Eckstein and Van den Berg, 2007; Rogerson et al., 2005), a discussion of our modeling approach is, however, necessary.

When considering the initial periods of the unemployment spell, a model with reservation wages leads to similar predictions as our model. The main intuition is that individuals with optimistic wage expectations set their reservation wages too high, and potentially adjust them downward too little over time. If reservation wages are binding, wage optimism thus leads to an increased rejection of wage offers and therefore reduces job finding. At the initial periods of the unemployment spell, this is in line with our model, which also predicts a reduced job finding hazard in response to optimism. In later periods, our model implies that optimism can also encourage search by the long-term unemployed, and thereby increase job finding. In a model with reservation wages, this effect would be counteracted by the increased rejection of wage offers due to optimism. We thus conclude that the two models imply similar behavioral reactions at initial periods of the unemployment spell, but potentially diverging reactions during later periods.

Unfortunately, we do not observe rejected offers in our data and can therefore not test for a reservation wage policy directly. Instead, we show that individuals do not appear to learn about wage offers, an indication that reservation wages may not be relevant (see section 4).

Finally, it is worth noting that acceptance of any wage offer is not the only possible interpretation of the search effort model. The model may also, as in Card et al. (2007), be 
viewed as one with a deterministic individual wage which is observed only with measurement error.

\section{Data}

Data Sources and Sampling We match administrative data on unemployed individuals from the German IAB Employment Biographies to survey data from the IZA Evaluation Dataset. The IZA Evaluation Dataset is a telephone survey of randomly chosen individuals who became unemployed and received payments from the German unemployment insurance (UI) between June 2007 and May 2008. ${ }^{9}$ The interviews are realized around 5 to 12 weeks after entry into unemployment. We restrict the analysis to individuals aged between 20 and 55 years, who worked full-time prior to unemployment, ${ }^{10}$ were unemployed for at least one full month and were searching for work. ${ }^{11}$ After these restrictions, 7,492 individuals are potentially part of the sample.

To measure the relationship between pre-unemployment wages, wage expectations and re-employment wages in a consistent way, we need to apply additional, non-standard sample restrictions. These ensure that our picture of optimistic wage expectations is not driven by confounding factors:

To focus on regular employment, we first exclude individuals whose net pre-unemployment monthly wage is below $631 €$ net, the level of social assistance (including housing benefits) for a single household $(\mathrm{N}=1032,13.7 \%)$. In addition, we drop individuals whose pre-unemployment wage is top-coded by the IAB at monthly $4,470 €$ gross $(\mathrm{N}=217,2.9 \%)$. For these individuals, it is impossible to infer the wage depreciation profile. We further exclude individuals whose self-reported pre-unemployment net wage exceeds the pre-unemployment gross wage reported in the administrative data $(\mathrm{N}=1118,14.9 \%)$. In these cases, self-reported and administratively reported wages are obviously inconsistent. ${ }^{12}$ This is problematic in our context, as we study both wage expectations and re-employment wages in relation to the pre-unemployment wage. We finally drop individuals who did not state a wage expectation although they were not yet re-employed at the time of the survey $(\mathrm{N}=402,5.4 \%) .{ }^{13}$ We do not exclude individuals who already found a job at the time of the interview and therefore do not have a stated

\footnotetext{
${ }^{9}$ Arni et al. (2014) provide a detailed description of the sampling method and content of the survey. The merged IZA/IAB data is described by Eberle et al. (2017).

${ }^{10}$ We exclude part-time workers to avoid that changes in working hours confound the wage effects we are interested in.

${ }^{11}$ Individuals who state that they are not searching for work are not asked for their wage expectation and are therefore not relevant for our analysis.

${ }^{12}$ Additionally, the administrative data can under-state the actual pre-unemployment gross wage in the cases of temporary sickness or maternity leave.

${ }^{13}$ We define an individual as re-employed when entering a job that exceeds monthly welfare benefits $(=$ monthly wage $>631 €)$ and lasts longer than one month. Individuals may consider themselves as re-employed when entering subsidized or marginal employment, and thus not answer the question on wage expectations.
} 
expectation. ${ }^{14}$ After applying these restrictions, the estimation sample contains 4,723 job seekers.

Measurement of Unemployment Duration and Wages The administrative data allow for a precise measurement of the realized unemployment duration, the pre-unemployment and the re-employment wage, the unemployment history and unemployment benefit payments. We observe entry into unemployment and can follow individuals until they are re-employed, independent of whether or not they receive unemployment benefits. Information on the employment status is reported on a monthly basis. An individual is defined as re-employed when entering a job whose wage exceeds monthly welfare benefits $(631 €)$ and which lasts longer than one month.

Measurement of Subjective Wage Expectations The survey data are used, in particular, to measure subjective wage expectations held by job seekers at the time of the survey, i.e., 5 to 12 weeks after entry into unemployment. The corresponding question is: "Now I am interested in your wage expectations concerning your next job. What do you expect to earn in net euros per month?" The wage expectation is naturally available only for job seekers who are still searching for work at the time of the interview. 720 individuals (15.2\%) had already found a job at the time of the interview and therefore do not state a wage expectation.

For individuals who participate in the second survey wave and who are still unemployed after one year, the data report a second wage expectation $(\mathrm{N}=628,13.3 \%)$. This information will be used to test for evidence of updating of expectations in both the descriptive analysis and the structural estimation.

Reported wage expectations are stated in net terms. As individuals also state their net preunemployment wage, we observe how much individuals expect to earn, in net terms, relative to their pre-unemployment wage. In the administrative data, wages are reported in gross terms. There, we observe how the gross re-employment wage relates to the gross pre-unemployment wage. ${ }^{15}$ To relate gross wages to net expectations, both in the descriptive analysis and the structural estimation, we convert gross re-employment wages into net terms according to the procedure described in appendix A. The procedure relies on both the theoretical tax schedule for 2008 and on the fact that we observe, for the same individual, pre-unemployment wages in both gross and net terms.

\footnotetext{
${ }^{14}$ In the estimation, these individuals contribute to the likelihood of job finding, but not to the likelihood of wage expectations.

${ }^{15}$ For individuals who enter re-employment within 12 months and participate at the second survey wave, we also observe the re-employment wage in net terms. Due to attrition and the limited time horizon, we do not rely on this measure.
} 
Summary Statistics Table 1 contains summary statistics on the variables used in the baseline estimation. The average pre-unemployment gross wage is at $1923 €$ gross per month. The average re-employment gross wage is $1,834 €$, i.e. $90 €$ below. In turn, the average net expectation is $120 €$ above the average net pre-unemployment wage.

[Insert Table 1]

\section{Descriptive Evidence}

In the following, we provide descriptive evidence on the realized and perceived evolution of wage offers after entry into unemployment. We first show that wages decrease with the time spent in unemployment. We then document that job seekers do not expect the fall in wage offers at the beginning of their spell, and that on average, they do not update their wage expectations later on.

Wage Depreciation Over the Unemployment Spell Figure 1 shows how average log monthly re-employment gross wages change with the realized duration of unemployment. Clearly, the average wage decreases over the spell. As illustrated by Figure 2, this pattern holds for all deciles of the wage distribution.

[Insert Figures 1 and 2]

Since wage levels may be correlated with the time spent in unemployment for various reasons, a more relevant measure of wage depreciation results from a comparison between reemployment and pre-unemployment wages. Figure 3 shows the same graph for the difference between the log re-employment and the log pre-unemployment wage. The average difference increases strongly over the spell. While individuals who remain unemployed up to 4 months lose around 2 to $3 \%$ relative to their pre-unemployment wage, longer spells are associated with significantly higher losses. In particular, individuals who are unemployed for longer than one year lose 10-20\% on average. According to a linear specification, the monthly depreciation factor is $-1.2 \%$, i.e., slightly above the $0.8 \%$ estimated with local discontinuities by Schmieder et al. (2016). Appendix figures A.2 to A.4 show the same pattern for net wages. Tax progression slightly alleviates the wage depreciation, which is here $1 \%$ per month according to a linear specification.

[Insert Figure 3] 
Subjective Expectations of Level of Wage Offers How do individuals perceive their wage prospects when entering unemployment? Figure 4 plots the sample distribution of the ratio of expected over pre-unemployment net wages. Clearly, most job seekers do not expect a wage loss. Almost $40 \%$ expect to earn a wage which is very close to their last wage, and more individuals expect to gain than to lose relative to their pre-unemployment wage. As illustrated by figure 5, this pattern results for many individuals in a gap between the expected and the realized net re-employment wage. Both the average and the median job seeker obtain only $90 \%$ of their expected wage.

In table A.1 of appendix B, we regress the ratio of the re-employment wage over the expected wage on individual job seeker characteristics, to get a sense of the degree of heterogeneity in wage optimism. Column 1 shows that the ratio of the re-employment wage over the expected wage decreases in the pre-unemployment wage. This suggests that individuals with high pre-unemployment wages receive a smaller share of their expected wage. A higher degree of education, work experience and prior unemployment experience are associated with a more realistic expectation, i.e., with a higher ratio. The pattern also holds in column 2 , where the dependent variable is an indicator for whether the ratio of the re-employment wage over the expected wage is lower than the sample median. While the table documents that the degree of optimism can be very heterogeneous across individuals, we focus in this paper on estimating the average effect of optimism on the exit from unemployment.

[Insert Figures 4 and 5]

Evolution of Subjective Wage Expectations A natural question arises: do individuals learn? Do individuals correct for their initial optimism while searching, i.e., is there evidence of learning over the unemployment spell? The data allow us to test for this in two ways. First, job seekers are initially interviewed at slightly different points in their unemployment spell, between week 5 and 12 after entry into unemployment. This provides a small degree of random variation in the time at which job seekers are asked for their initial expectation. Figure 6 plots the ratio of expected over last wages by the week of interview. It clearly shows that the distribution of expectations does not change over this time window: job seekers with 5 weeks of elapsed unemployment do not hold different expectations than job seekers whose elapsed unemployment is 12 weeks.

\section{[Insert Figure 6]}

As an additional source of variation in the timing of stated expectations, we use panel dimension, which is available for individuals participating at the second survey wave and still being unemployed in this period, i.e., after 12 months $(\mathrm{N}=628)$. Figure 7 plots the ratio 
of wage expectations reported in the second wave against the initial expectation of these individuals. It shows that more than $30 \%$ of job seekers maintain their initial expectation after one year in unemployment. The average and median job seeker perform zero updating. Although individuals still unemployed after a year are a selective group and despite attrition, the pattern suggests that there is on average no relevant updating of wage expectations over the spell. This observation is in line with reservation wage data collected by Krueger and Mueller (2016), who show that the reservation wages of U.S. workers hardly adapt over the unemployment spell. Koenig et al. (2016) confirm the notion of reference dependence in reservation wages for UK and West German job seekers. Further, Hoffman and Burks (2017) document the absence of belief updating in a different labor market context. They show that truck drivers over-estimate the number of miles they will run over the pay week, without updating their beliefs over the week.

\section{[Insert Figure 7]}

\section{Structural Estimation}

The descriptive evidence indicates a neglect of actual wage dynamics by job seekers. From there, we can, however, not conclude whether this mis-perception (adversely) affects individual behavior. In the following, we want to find out whether "wage optimism" affects job search and the duration spent in unemployment. To this end, we set up a structural analysis of job search under subjective wage expectations.

In the following, we discuss the likelihood function, econometric specification and identification of the model presented in section 2. Our goal is to obtain parameter estimates allowing to simulate how search behavior changes after the imposition of perfect information on actual wage opportunities.

\subsection{Likelihood Function}

We estimate the non-stationary job search model with subjective beliefs about wage offers using maximum likelihood. The likelihood function describes the joint density of observed wages $w_{i}$, job search durations $d_{i}$, and wage expectations $w_{i}^{e x p}$. The parameter vector $\phi$ contains the wage offer distributions $F_{t}$, the benefit levels $b_{t}$, the utility function $u$, as well as the search cost function $c_{t}$. We allow subjective wage expectations to be subject to measurement error, with $\varepsilon^{e x p} \equiv \log \left(\widetilde{w}^{\exp }(\phi)\right)-\log \left(w^{e x p}\right)$, where $w^{\text {exp }}$ is the reported subjective wage expectation and $\widetilde{w}^{e x p}(\phi)$ the underlying subjective wage expectation. Denote the density of the measurement error as $h_{\exp \mid \phi}$. The likelihood contribution for an uncensored observation $i$ 
whose unemployment spell ends in month $d_{i}$ is:

$$
\mathcal{L}_{i}^{\text {uncens }}(\phi)=\prod_{\eta=1}^{d_{i}-1}\left(1-s_{\eta}(\phi)\right) h_{e x p \mid \phi}\left(w_{\eta}^{e x p} \mid \widetilde{w}_{d_{i}}^{e x p}(\phi)\right)^{d_{\eta}^{e x p}} s_{d_{i}}(\phi) f_{d_{i}}^{o b j}\left(w_{i} \mid \phi\right)
$$

where $d_{\eta}^{\text {exp }}$ indicates if a wage expectation is observed in period $\eta$. Similarly, for observations censored at time $t=T_{C}$ (here: 20 months), we have:

$$
\mathcal{L}_{i}^{\text {cens }}(\phi)=\prod_{\eta=1}^{T_{C}}\left(1-s_{\eta}(\phi)\right) h_{\exp \mid \phi}\left(w_{\eta}^{e x p} \mid \widetilde{w}_{\eta}^{e x p}(\phi)\right)^{d_{\eta}^{e x p}}
$$

\subsection{Econometric Specification}

Utility is logarithmic in income, implying the absence of savings as in Frijters and van der Klaauw (2006). Individuals employed at wage $w$ derive logarithmic utility from their net wage, $\tau(w): u(w)=\log (\tau(w))$. The conversion of gross wages into net terms follows the procedure described in appendix A. When unemployed with benefits $b_{t}$, individuals have utility $u(b)=\log \left(b_{t}\right)$. Unemployed agents receive wage offers from a log-normal distribution, $w_{t} \sim$ $\mathcal{N}\left(\mu_{t}^{w}, \sigma_{w}\right)$, where the level of wage offers $\mu_{0}$ is allowed to depend on individual characteristics $X$. The dependence on $X$ is parameterized by the vector $\beta^{\mu}$, which also includes a constant term. We suppress individual subscripts to ease notation. Over time, the mean of the wage offer distribution depreciates at rate $\theta^{o b j}$,

$$
\begin{aligned}
\mu_{t}^{w} & =\mu_{0}-\theta^{o b j} t, \\
\mu_{0} & =\beta^{\mu} X .
\end{aligned}
$$

As in Paserman (2008) and DellaVigna et al. (2017), we assume the search cost function to be of power form:

$$
\begin{aligned}
c_{t}(s) & =e_{t} \frac{s^{1+\gamma}}{1+\gamma}, \\
e_{t} & =\exp \left(\beta^{e} X-\theta^{e} t\right) .
\end{aligned}
$$

The search cost component $e_{t}$ is allowed to vary with individual characteristics $X$, which is parametrized by $\beta^{e}$ (including a constant term). $e_{t}$ can evolve geometrically with time, as measured by the cost-depreciation factor $\theta^{e}$. For instance, search can become more costly over the unemployment spell, because easily available offers become exhausted or because motivation decreases. Other elements of duration dependence, not contained in the other model parameters, may also enter $\theta^{e}$.

As noted by DellaVigna et al. (2017), the search cost parameter $\gamma$ is the inverse elasticity 
of the search intensity to the net value of unemployment, $\left(\mathrm{E}_{F_{t}^{s u b}} V(w)-U_{t}\right) / e_{t}$. Both for wage offers and for search costs, the vector of observable characteristics $X$ includes the last wage received before entrance into unemployment (in addition to gender, education, as well as prior work and unemployment experience). These control for differences in ability or productivity, which may cause selection into prolonged unemployment. We discuss the role of unobserved heterogeneity below, in section 5.3.

\subsubsection{Subjective Wage Expectations}

The survey data report subjective net wage expectations $w_{t}^{e x p}$ at different points early in the unemployment spell (between week 5 and 12). Some individuals also report a second subjective wage expectation after about 12 months of unemployment. Formally, we interpret the underlying subjective net wage expectation as a weighted average of future subjective wage offers:

$$
\begin{aligned}
\widetilde{w}_{t}^{e x p}(\phi) & =\sum_{\eta=0}^{\infty} \operatorname{Prob}(d=t+\eta \mid \phi) \mathrm{E}_{F_{t+\eta}^{s u b}} \tau(w) \\
& =\sum_{\eta=0}^{\infty} S_{t, t+\eta}(\phi) s_{t+\eta}(\phi) \mathrm{E}_{F_{t+\eta}^{s u b}} \tau(w)
\end{aligned}
$$

where $d$ is the duration of unemployment and $S_{t, t+\eta}(\phi)=\operatorname{Prob}(d \geq t+\eta \mid d \geq=t, \phi)$ is the survival probability from $t$ to $t+\eta$, given the model parameters $\phi . F_{t}^{s u b}$ denotes the subjective wage offer distribution at time $t$ characterized by $\mathcal{N}\left(\mu_{t}^{w, s u b}, \sigma_{w}\right)$, where

$$
\mu_{t}^{w, s u b}=\mu_{0}-\theta^{s u b} t+\alpha^{s u b}
$$

In this specification, an individual's subjective wage distribution may differ from the true wage offer distribution in two regards. First, there may be a different perception of the rate at which mean wage offers depreciate during the unemployment spell, i.e., $\theta^{s u b} \neq \theta^{o b j}$. Second, there may be a misperception of the overall level of wage offers, such that $\alpha^{s u b} \neq 0$. Thus, wage optimism may be characterized by $\theta^{s u b}<\theta^{o b j}$, or $\alpha^{s u b}>0$, or both.

We assume that the measurement error of the wage expectation is normally distributed, i.e., $\varepsilon_{\text {exp }, t} \sim \mathcal{N}\left(0, \sigma_{\text {exp }}\right)$.

\subsection{Identification}

The central parameters in our job search model are the rate of wage depreciation $\theta^{o b j}$ and its subjective counterpart $\theta^{s u b}$, as well as the level parameter of wage optimism $\alpha^{s u b}$. Since 
the model abstracts from reservation wage choices, ${ }^{16}$ we identify the full path of wage offer

distributions $F_{t}^{o b j}$, hence $\theta^{o b j}$ and $\sigma_{w}$, from accepted wages at different job search durations $t$. This naturally also holds for all combinations of the vector $X$, such that $\beta^{\mu}$ is identified as well. The parameters of the subjective counterparts of the wage distribution, denoted by $\theta^{\text {sub }}$ and $\alpha^{s u b}$, are identified by the (repeated) observations of the subjective wage expectations for different duration outcomes.

In the model, the job finding effort depends on the net value of employment, $\left(V_{t}-U_{t}\right) / e_{t}$, and the costs of search, $c_{t}\left(s_{t}\right)$. The optimal level of search given the net value of unemployment is defined by $s_{t}=\left(\left(V_{t}-U_{t}\right) / e_{t}\right)^{1 / \gamma}$. We identify $\beta^{e}$ from the scale of the hazard function and the differences between subgroups defined by $X$. Furthermore, $\gamma$ determines how sensitive the hazard function is to time-varying unemployment benefits. It follows that for groups of individuals with the same benefit path and observable characteristics, duration dependence in the job finding hazard identifies the parameter of search cost dynamics $\theta^{e}$.

We include past wages as a component of the vector of covariates $X$ to control for heterogeneity between individuals in the average wage offer $\mu_{w}$ and in the cost of effort parameter $e$. In the context of job search, controls for the labor market history have been shown to be a powerful tool to control for (usually unobserved) heterogeneity between unemployed individuals (see, e.g., Caliendo et al., 2017, who for the data used in this paper). We, however, acknowledge that we cannot fully exclude the possibility of remaining unobserved heterogeneity. Such heterogeneity would mostly lead to an over-estimation of $\theta^{e}$, which is identified from duration dependence conditional on $X$.

Following the estimates obtained by Frijters and van der Klaauw (2006) for German individuals, set the discount rate to $20 \%$ p.a., which is equivalent to a monthly discount rate of $r=1.53 \%$. In our setting, it is difficult to disentangle the parameter values of $\gamma$ and $r$, since both respond to variation in individual benefit and wage and benefit paths over the spell. As in Frijters and van der Klaauw (2006), we assume that job finding is an absorbing state, motivating the relatively high baseline discount rate of $20 \%$. To assess the sensitivity of our policy effects with respect to the chosen discount rate, we provide results based on estimations with $r=0.01$ and $r=0.02$, as lower and upper bounds, respectively, in section 6.3.2.

\section{$6 \quad$ Estimation Results}

We first report parameter estimates and the fit of the job search model with subjective wage expectations. We then use the estimates of the subjective expectations model to simulate a scenario in which individuals are perfectly informed about their wage prospects. On this basis, we discuss the effect of wage optimism on the duration to re-employment, re-employment

\footnotetext{
${ }^{16} \mathrm{Cf}$. section 2 for a discussion of this modeling choice.
} 
wages, and UI benefit payments.

\subsection{Parameter Estimates}

Table 2 shows parameter estimates based on the likelihood specified by equations 9 and 10, where the discount rate is set to $r=1.53 \%$ per month. The mean subjective wage expecta-

tion for period $\mathrm{t}, \mu_{t}^{w, s u b}$, is composed of the average initial wage level, $\mu_{0}$, the level difference between expected and actual wage offers, $\alpha^{s u b}$, and the subjective wage depreciation factor, $\theta^{\text {sub }}$ (cf. equation 17). Results show that, as expected, the average re-employment wage $\mu_{0}$ increases in the pre-unemployment wage and education, and is lower for females. Conditional on these variables, work experience and unemployment experience have no significant influence. The level parameter of wage optimism, $\alpha^{s u b}$, indicates that job seekers over-estimate their future re-employment wage level by $7 \%$ on average. The estimated subjective wage offer depreciation rate, $\theta^{s u b}$, is not different from zero, implying that individuals do not anticipate their wage offers to fall. The actual wage depreciation factor, $\theta^{o b j}$, is estimated to be $1.2 \%$ per month of unemployment. Therefore, individuals are on average wage optimistic both with respect to the wage offer level, and with respect to its depreciation.

Search costs increase in pre-unemployment wages and are about $35 \%$ higher for female job seekers. The estimate of $\theta^{e}$ suggests that search costs increase by about $37 \%$ per month of unemployment. This is in line with the intuition that job seekers have increasing difficulties in generating job offers.

\section{[Insert Table 2]}

\subsection{Model Fit}

Figures 8 to 10 illustrate how the model fits the data. They plot model predictions based on 1,000 independent random draws for each of the 4,723 individuals in the sample, using the parameter estimates reported in table 2.

As shown by figure 8, job finding exhibits strong negative duration dependence in the data. The job finding hazard starts out from about 15 to $17 \%$ and declines to as little as $3 \%$ after 20 months. This pattern is well captured by the model. Figures 9 to 10 show histograms for the fit of gross re-entry wages and net wage expectations, respectively. Both wage measures are well predicted by the model.

[Insert Figures 8 to 10$]$ 


\subsection{Simulation: The Effects of Wage Optimism on Job Finding}

We now quantify the impact of wage optimism on job finding. To this end, use the parameter estimates to simulate a scenario in which individuals are perfectly informed about future wage offers. We first report baseline results and then assess how sensitive the results are with respect to the choice of the discount factor. All simulations are based on 1,000 independent random draws for each of the 4,723 individuals, using the parameter estimates reported in table 2 .

\subsubsection{Baseline Results}

To understand how wage optimism affects job finding, we simulate a counter-factual scenario in which job seekers are fully aware of the path of wage offers over the progression of unemployment. To this end, we estimate the subjective expectations model while imposing $\alpha^{s u b}=0$ and $\theta^{s u b}=\theta^{o b j}$. In terms of policy, we predict the effects of an intervention in which the average job seeker is provided with perfect information about their wage profiles. We simulate a policy that leads to a full adjustment of individual wage expectations to actual wage offer distributions. This is, of course, an ideal that is unlikely reached in practice. However, well-designed counseling, or an "information treatment" will likely lead to a partial adjustment of subjective wage expectations. Therefore, we use our simulation results to understand the dynamic reactions of job search to optimism, and to measure an upper bound on the potential effect of information provision.

We contrast the effect of information provision with the effect of a $10 \%$ reduction in search costs $e_{t}$ in each month $t$ of the spell. From a policy perspective, search costs can for instance be reduced by offering support with application writing or by referring suitable vacancies.

\section{[Insert Figure 11]}

Figure 11 plots predicted percentage changes in the job finding hazard over the spell. In line with intuition, the search cost reduction has unambiguously positive effects on job finding. Given that search costs increase over the spell (due to a positive estimate of $\theta^{e}$ ), the benefits of a $10 \%$ cost reduction also follow a slightly increasing pattern. Overall, job-finding increases by around $2-3 \%$.

By contrast, the information treatment shows highly dynamic effects over the course of the unemployment spell. As wage losses can be avoided by exiting at an earlier stage, perfectly informed individuals are around $8 \%$ more likely to find a job during the first month of unemployment. This effect sharply decreases over the spell and reaches a point estimate of zero in month seven. From then onward, perfect information reduces incentives to search and the job finding probability decreases by up to $15 \%$ in month 20 . This simulated pattern sheds light 
on the qualitative predictions discussed in section 2: at the beginning of the unemployment spell, the prospect of falling wage offers creates an incentive to search more today. Under wage optimism, this incentive is absent, which explains that the counter-factual with perfect information predicts more individuals finding a job very early on. For individuals who remain unemployed, rational expectations reduce the motivation to search: informed individuals now realize that they have lower returns from searching, since the quality of their wage offers has depreciated.

In table 3, we report how the change to perfect information affects the average duration of unemployment, the amount of benefit payments and wages. Given that a large share of individuals exits unemployment at early stages, the average duration to re-employment reduces substantially in response to the provision of information, by about 0.7 months $(\approx 6.5 \%)$. As a consequence, benefit payments per person fall by around $452 €(\approx 6 \%)$ per person. As the average individual avoids nearly one month of wage depreciation, the average re-employment wage increases by about $1 \%$. The $10 \%$ search cost reduction reduces unemployment and benefit payments by about $2 \%$ and increases wages by about $0.1 \%$.

\section{[Insert Table 3]}

Taken together, the simulation illustrates an economically significant potential to increase early job finding by raising the awareness about falling wage offers. This benefit, however, comes at the price of discouragement among long-term unemployed workers, rendering overall policy implications ambiguous.

\subsubsection{Sensitivity to the Chosen Discount Factor}

As evoked in section 5.3, the estimated returns to information may be influenced by the chosen discount factor $r$. Setting $r$ too low may lead us to over-estimate the effect of information provision on job finding: more patient job seekers find a decrease in future wage offers more salient, such that initial job search shows stronger reactions to future wage offer reductions. Setting the discount rate too high has the opposite effect of under-estimating the role of information provision. By contrast, the estimated effect on search at later stages of the spell is unlikely to be affected, as it is mostly driven by changes in current payoffs.

To provide evidence on the sensitivity of predicted effects to the discount factor, we estimate the effect of optimism for a low value of $r=1 \%$, and for a high value of $r=2 \%$. The corresponding parameter estimates are reported in tables A.2 and A.3 of appendix C. Figure 12 shows that the qualitative pattern of the policy effect looks very similar across discount factors. However, the initial effect sizes vary: for the lower bound of $r=1 \%$, the initial increase in the job finding hazard due to information starts off at around $12 \%$ and becomes 
zero only in month 11 . This reflects that patient individuals initially perceive future wage losses as being more salient. In turn, the effects simulated with the upper bound of $2 \%$ are only slightly more negative than those from the baseline with $r \approx 1.5 \%$. The effect of the information treatment for longer-term unemployed (12+ months) does not depend on the chosen discount rate. This is expected, as the decision to search is less influenced by future payoffs when the stationary period approaches.

Given that job finding predominantly occurs at the beginning of a spell, the size of average effects reacts to the choice of $r$. As reported in table 4, the duration in unemployment is predicted to decrease by $10 \%$ for $r=1 \%$, compared to an increase by $6.5 \%$ in the baseline case with $r=1.53 \%$ and an increase by $5 \%$ for $r=2 \%$.

We conclude that the exact initial effect sizes are sensitive to the choice of the discount factor. However, we can confirm the robustness of the following findings. First, the potential effect of information about wage opportunities on job finding is economically significant. Second, the effect is initially positive and switches signs later in the spell. It is in our setting unambiguously positive in the first six months, and unambiguously negative for spells lasting longer than a year.

\section{[Insert Figure 12 and Table 4]}

\section{Conclusion}

We combine data on subjective expectations with data on realized job search outcomes. We show that job seekers significantly over-estimate their future wage outcomes, by $10 \%$ on average.

We build a structural job search model that accounts for the divergence of subjective beliefs from the true wage offer distribution. Based on simulations of a counter-factual with perfect information, we find that wage optimism increases the average unemployment duration by around 0.7 months $(6.5 \%)$. However, this average effect masks important dynamics: more information leads individuals to increase their search effort over the first few months of unemployment. During this time, the information about future reductions in job offer quality raises the incentive to search for a job. For longer-term unemployed individuals, who are already affected by deteriorated wage offers, information lowers the search incentive and therefore reduces job finding. This implies a cautionary note for efforts aimed at informing job seekers better about the dynamics of their job search environment: care needs to be taken not to discourage the long-term unemployed.

Finally, our study suggests an easy-to-implement test for potential mis-specification in dynamic job-search models: combining the use of actually observed declines in wage offers 
with the assumption of a static subjective wage offer distribution, to account for the fact that individuals do not anticipate the depreciation of wages. This procedure can serve as a useful robustness check for policy simulations based on search models whenever data on subjective wage expectations is not available. 


\section{References}

Altmann, S., A. Falk, S. Jäger, And F. Zimmermann (2017): "Learning about Job Search: A Field Experiment with Job Seekers in Germany," Journal of Public Economics, forthcoming.

Arni, P., M. Caliendo, S. Kuenn, and K. Zimmermann (2014): "The IZA Evaluation Dataset Survey: A Scientific Use File," IZA Discussion Paper.

Arni, P. And C. Wunsch (2014): "Report No. 62: Die Rolle von Erwartungshaltungen in der Stellensuche und der RAV-Beratung (Teilprojekt 1)," Tech. rep., Institute for the Study of Labor (IZA).

Blundell, R., L. Pistaferri, and I. Saporta-Eksten (2016): "Consumption inequality and family labor supply," American Economic Review, 106, 387-435.

Caliendo, M., D. A. Cobb-Clark, and A. Uhlendorff (2015): "Locus of Control and Job Search Strategies," Review of Economics and Statistics, 97, 88-103.

Caliendo, M., R. Mahlstedt, and O. A. Mitnik (2017): "Unobservable, but Unimportant? The Influence of Personality Traitsand Other Usually Unobserved Variables for the Evaluation of Labor Market Policies," Labour Economics, 46, 14-25.

Card, D., R. Chetty, and A. Weber (2007): "Cash-On-Hand and Competing Models of Intertemporal Behavior: New Evidence from the Labor Market," Quarterly Journal of Economics, 122(4), 1511-1560.

DellaVigna, S., A. Lindner, B. Reizer, And J. Schmieder (2017): "ReferenceDependent Job Search: Evidence from Hungary," Quarterly Journal of Economics, 4, 1969-2018.

Della Vigna, S. And D. Paserman (2005): "Job Search and Impatience," Journal of Labor Economics, 23, 527-588.

Eberle, J., R. Mahlstedt, And A. Schmucker (2017): "IZA/IAB Linked Evaluation Dataset 1993-2010," FDZ Datenreport.

Eckstein, Z. AND G. VAn DEN Berg (2007): "Empirical Labor Search: A Survey," Journal of Econometrics, 136, 531-464.

ErIKsson, S. And D.-O. Rooth (2014): "Do Employers Use Unemployment as a Sorting Criterion When Hiring? Evidence from a Field Experiment," American Economic Review, 104(3), 1014-39. 
Frijters, P. And B. VAn DeR KlaAuw (2006): "Job Search with Nonparticipation," The Economic Journal, 116, 45-83.

Heathcote, J., K. Storesletten, And G. L. Violante (2014): "Consumption and labor supply with partial insurance: An analytical framework," American Economic Review, 104, $2075-2126$.

Hoffman, M. And S. Burks (2017): "Worker Overconfidence: Field Evidence and Implications for Employee Turnover and Returns from Training," mimeo.

Koenig, F., A. Manning, and B. Petrongolo (2016): "Reservation wages and the wage flexibility puzzle," mimeo.

Kroft, K., F. Lange, and M. Notowidigdo (2013): "Duration Dependence and Labor Market Conditions: Evidence from a Field Experiment," Quarterly Journal of Economics, $128(3), 1123-1167$.

Krueger, A. B. And A. I. Mueller (2016): "A Contribution to the Empirics of Reservation Wages," AEJ: Economic Policy, 8(1), 142-79.

Lentz, R. And T. Tranaes (2005): "Job Search and Savings: Wealth Effects and Duration Dependence," Journal of Labor Economics, 23, 467-490.

Paserman, D. (2008): "Job Search and Hyperbolic Discounting: Structural Estimation and Policy Evaluation," Economic Journal, vol. 118(531), 1418-1452, 08.

Rogerson, R., R. Shimer, And R. Wright (2005): "Search-Theoretic Models of the Labor Market: A Survey," Journal of Economic Literature, 43, 959-988.

Schmieder, J. F., T. von Wachter, And S. Bender (2016): "The Effect of Unemployment Benefits and Nonemployment Durations on Wages," American Economic Review, 739-777.

SpinnewiJn, J. (2015): "Unemployed but optimistic: Optimal insurance design with biased beliefs," Journal of the European Economic Association, 13, 130-167.

VAn Den Berg, G. J. (1990): "Nonstationarity in job search theory," The Review of Economic Studies, 57, 255-277.

Wolpin, K. I. (1987): "Estimating a Structural Search Model: The Transition from School to Work," Econometrica, 55, 801-817. 


\section{Figures}

Figure 1: Re-Employment Log Wage (Gross)

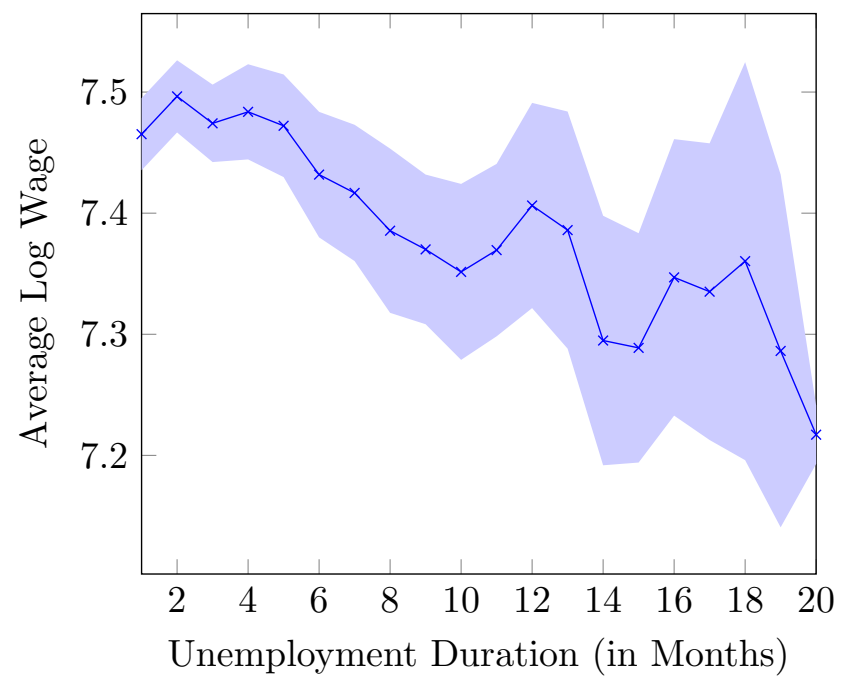

Source: IAB Employment Biographies. The shaded area shows $95 \%$ confidence bands. The graph includes individuals who enter re-employment within 20 months $(\mathrm{N}=3,592)$.

Figure 2: Deciles of Re-Employment Log Wage (Gross)

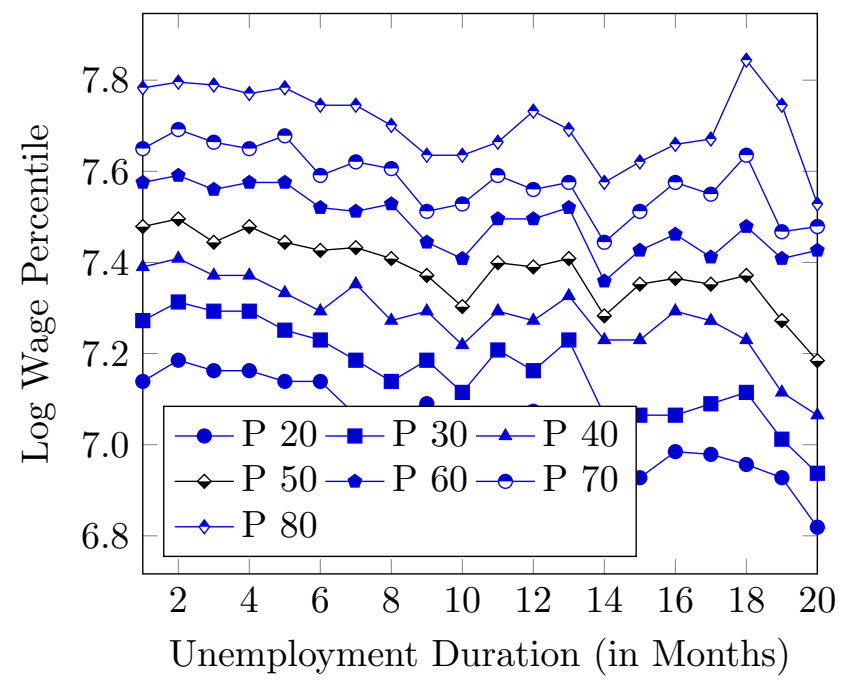

Source: IAB Employment Biographies. The graph includes individuals who enter re-employment within 20 months $(\mathrm{N}=3,592)$. 
Figure 3: Re-Employment Minus Pre-Unemployment Log Wage (Gross)

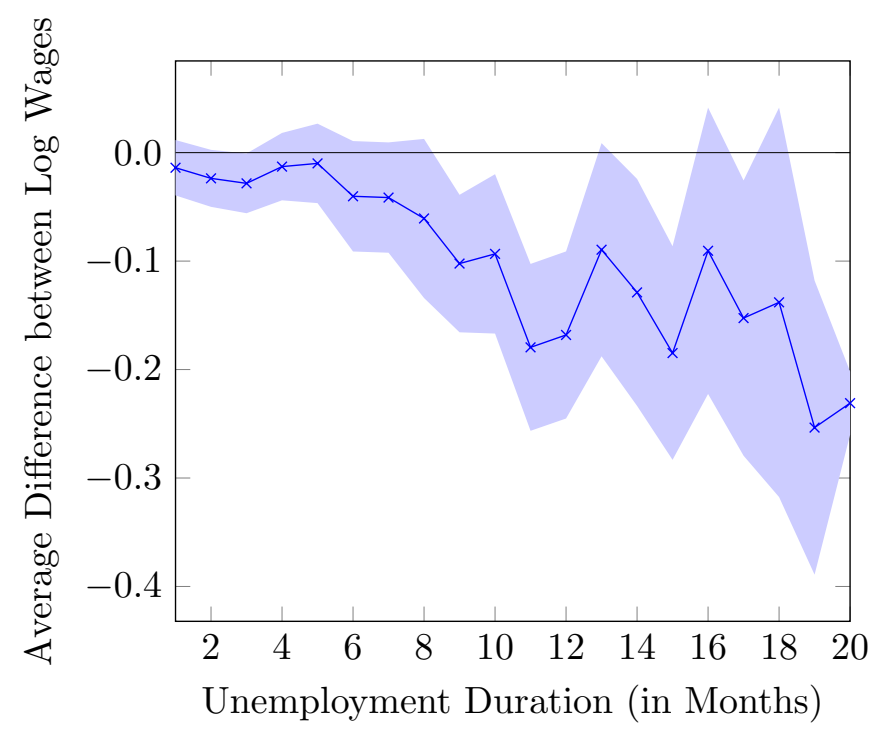

Source: IAB Employment Biographies. The shaded area shows $95 \%$ confidence bands. The graph includes individuals who enter re-employment within 20 months $(\mathrm{N}=3,592)$.

Figure 4: Initial Wage Expectation over Pre-Unemployment Wage (Net)

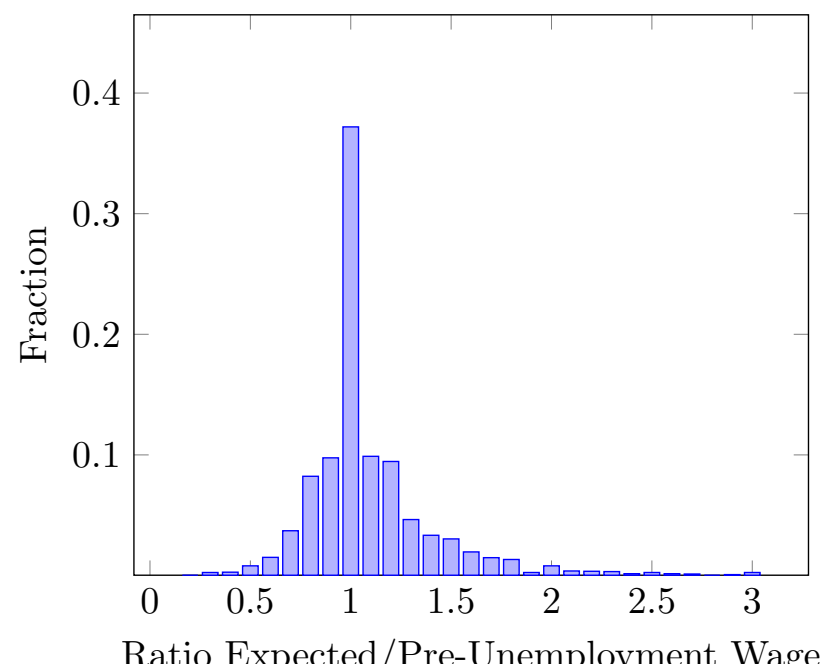

Source: IAB Employment Biographies (pre-unemployment wage) and IZA Evaluation Dataset (wage expectation). The graph includes individuals who have not entered re-employment at the interview date $(\mathrm{N}=4,005)$. Individuals with a ratio larger than 3 are excluded from the graph $(<1 \%)$ 
Figure 5: Re-Employment Wage over Wage Expectation (Net)

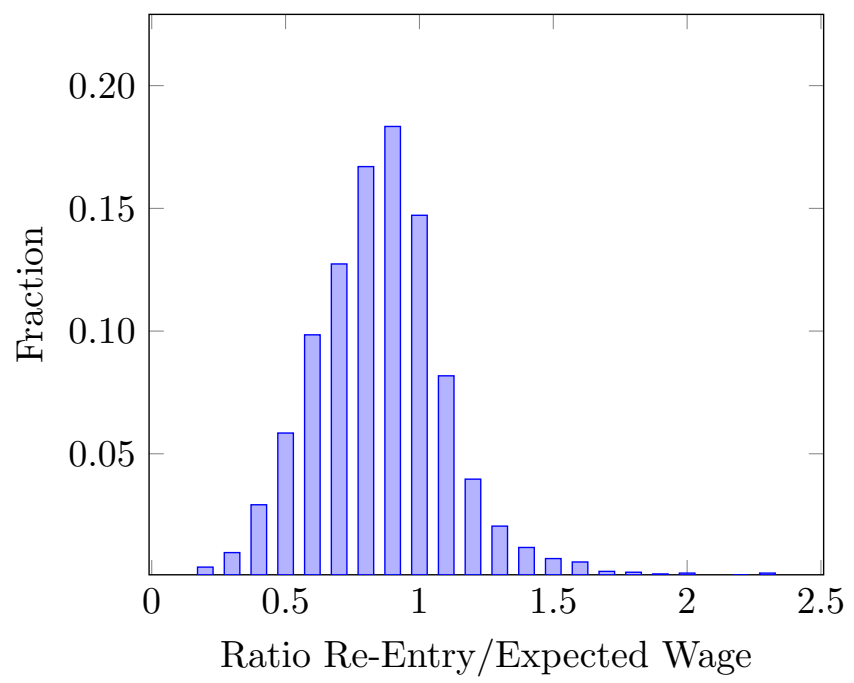

Source: IAB Employment Biographies (re-employment wage) and IZA Evaluation Dataset (wage expectation). The graph includes individuals who have not entered re-employment at the interview date and who enter re-employment within 20 months $(\mathrm{N}=2,874)$.

Figure 6: Subjective Wage Expectations (Net), by Week of Interview

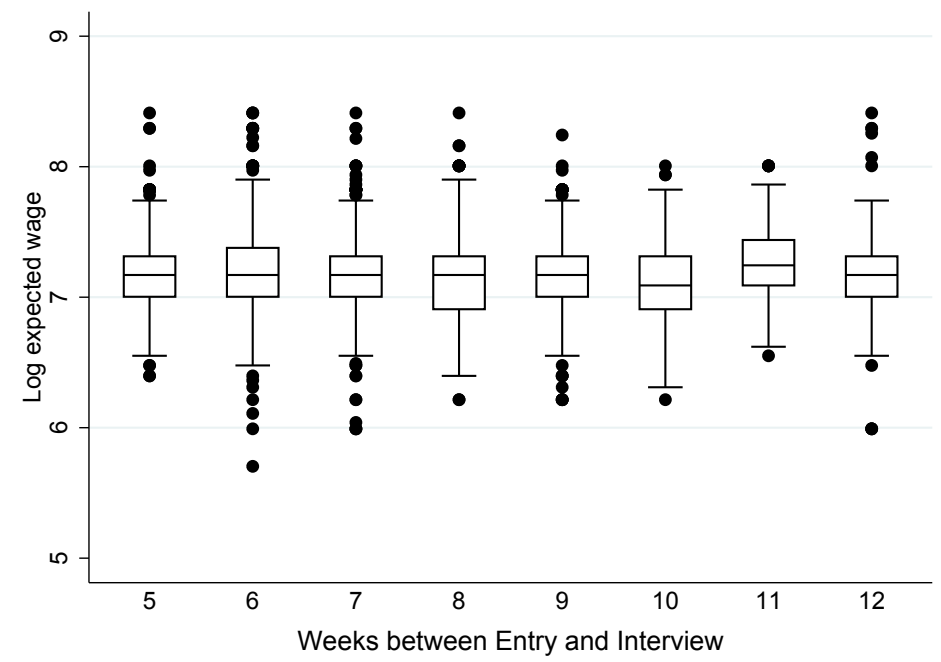

Source: IZA Evaluation Dataset. The graph shows box plots on initial (log) net wage expectations over the job seeker's week of interview. The upper line of the box shows $75^{\text {th }}$ percentiles, the line inside the box shows medians and the lower line shows $25^{\text {th }}$ percentiles. Dots show outside values. The graph includes individuals who have not entered re-employment at the interview date $(\mathrm{N}=4,005)$. 
Figure 7: Net Wage Expectation in Wave 1 over Net Wage Expectation in Wave 2

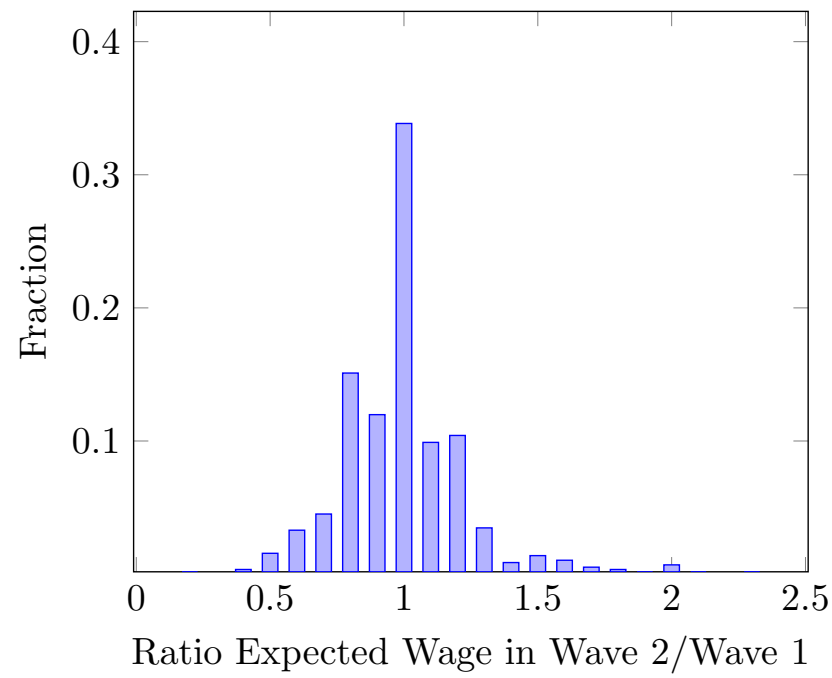

Source: IZA Evaluation Dataset. Wave 1 takes place between 5 and 11 weeks after entry into unemployment. Wave 2 re-interviews all available job seekers after 12 months of unemployment. The graph includes individuals with a stated wage expectation in waves 1 and $2(\mathrm{~N}=628)$.

Figure 8: Fit of Job Finding Hazard

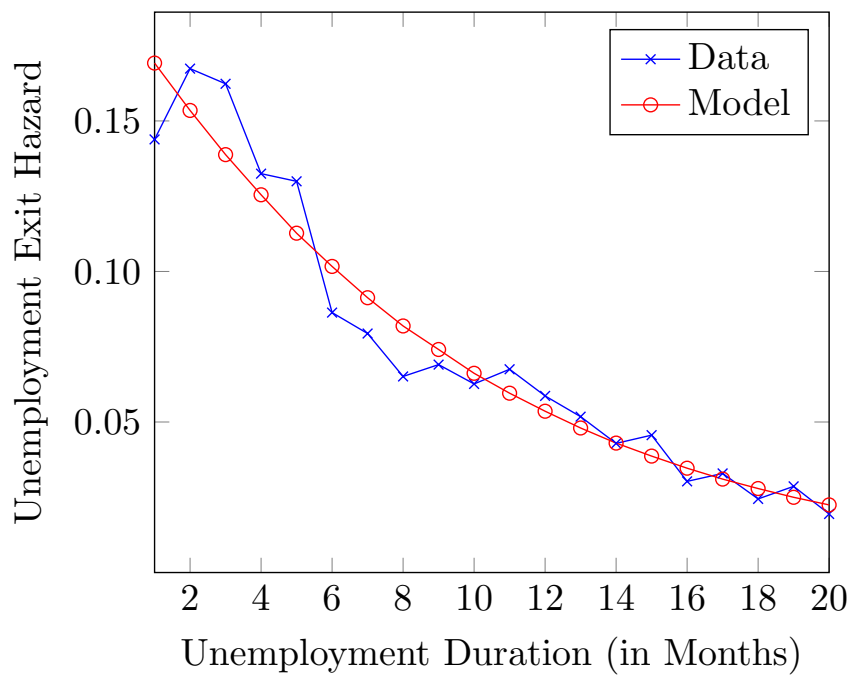

Predictions are made based on the parameter estimates reported in table 2. 
Figure 9: Fit of Re-Employment Wages

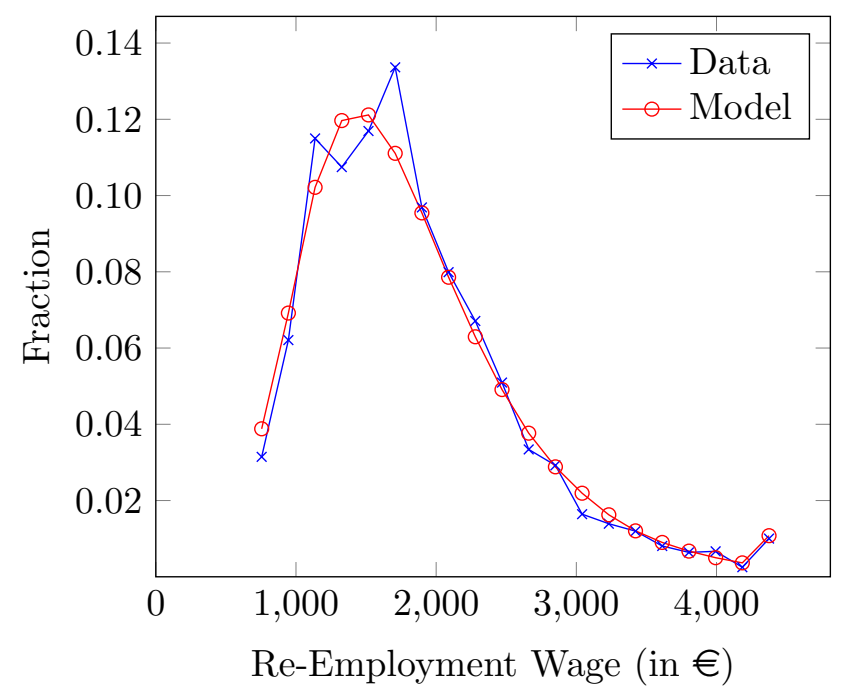

Predictions are based on 1,000 independent random draws for each of the 4,723 individuals in the sample, using the parameter estimates reported in table 2 .

Figure 10: Fit of Subjective Wage Expectations

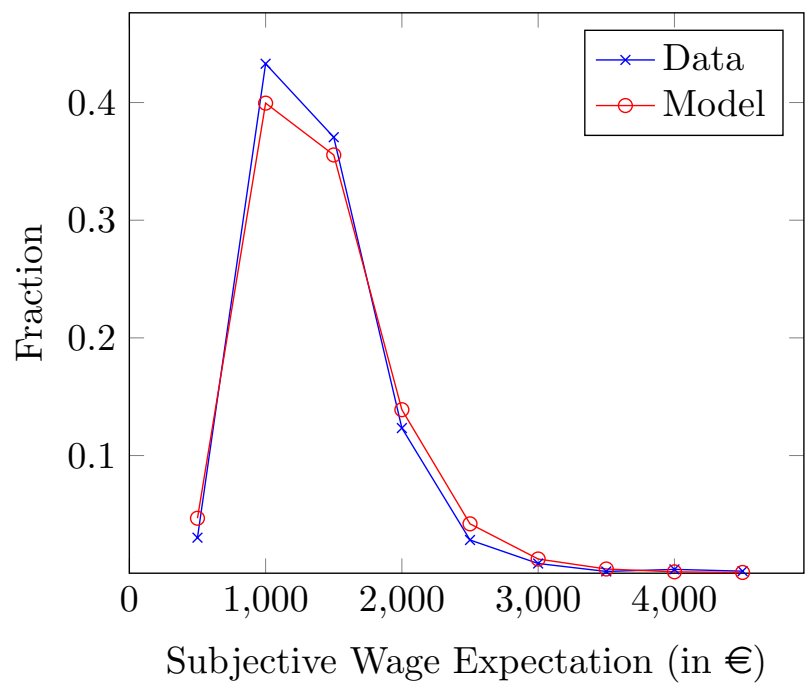

Predictions are based on 1,000 independent random draws for each of the 4,723 individuals in the sample, using the parameter estimates reported in table 2 . 
Figure 11: Simulation: Effect of Information Provision and Search Cost Reduction

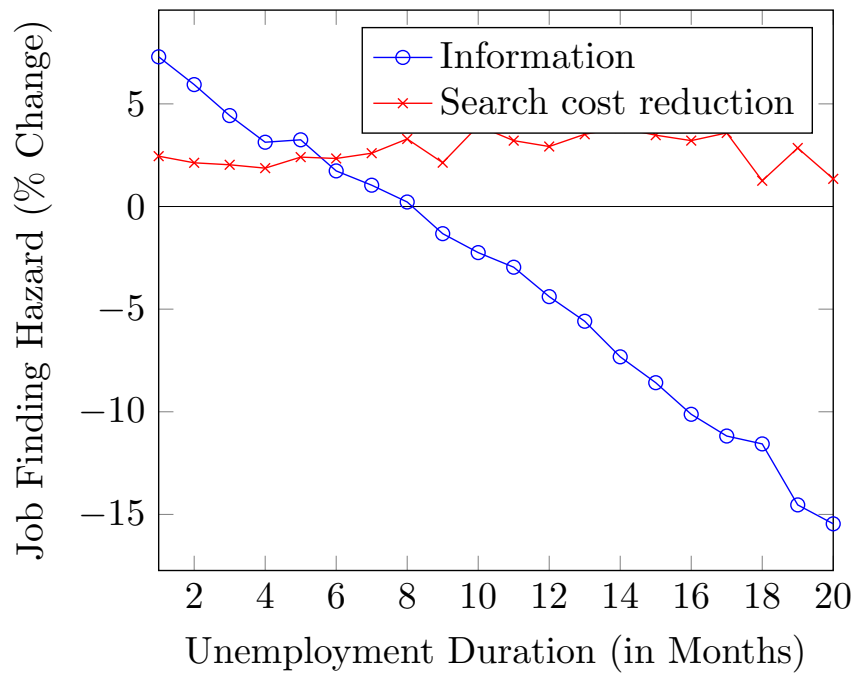

The counter-factual simulations are based on 1,000 independent random draws for each of the 4,723 individuals in the sample. The information treatment imposes perfect information about wage offers by setting $\alpha^{s u b}=0$ and $\theta^{s u b}=\theta^{o b j}$. The simulated search cost reduction reduces $e_{t}$ by $10 \%$ at each month of the spell.

Figure 12: Simulation: Effect of Information Provision for Different Discount Factors

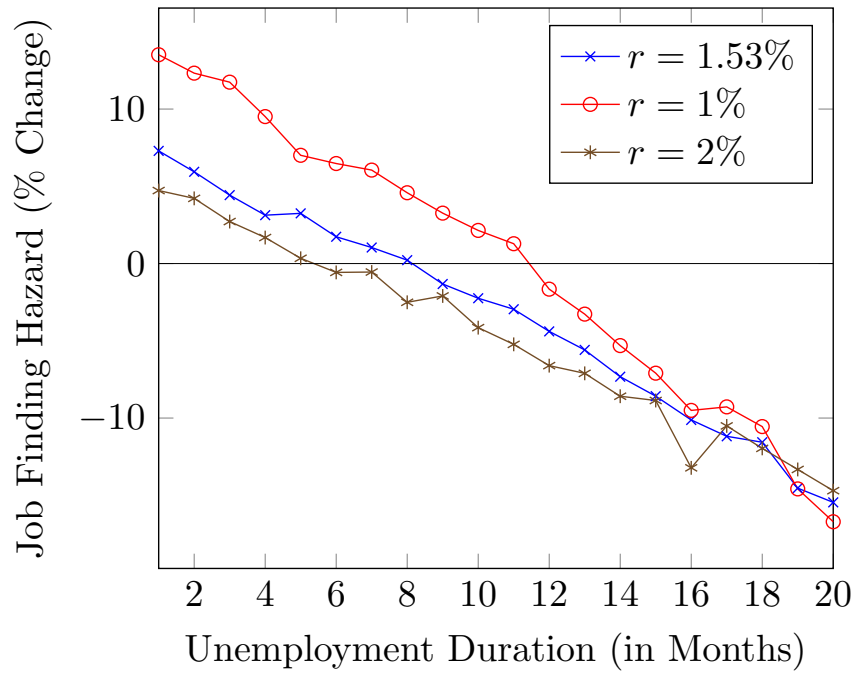

The counter-factual simulations are based on 1,000 independent random draws for each of the 4,723 individuals in the sample. The information provision imposes perfect information about wage offers by setting $\alpha^{\text {sub }}=0$ and $\theta^{s u b}=\theta^{o b j}$ 


\section{Tables}

Table 1: Summary Statistics

\begin{tabular}{lcccc}
\hline Variable & Obs & Mean & Std. Dev. & Data Source \\
\hline UE Duration & 4,723 & 8.891 & 7.373 & Admin \\
Censored at T=20 & 4,723 & 0.239 & 0.427 & Admin \\
Gross Pre-UE Wage & 4,723 & 1923.125 & 744.296 & Admin \\
Net Pre-UE Wage & 4,723 & 1261.724 & 420.055 & Survey \\
Gross Re-Employment Wage & 3,592 & 1834.001 & 718.793 & Admin \\
Net Re-Employment Wage & 3,592 & 1227.857 & 434.990 & Admin, own calculation \\
Net Expected Wage, Wave 1 & 4,005 & 1380.496 & 461.211 & Survey \\
Net Expected Wage, Wave 2 & 628 & 1364.229 & 456.119 & Survey \\
& & & & \\
Education: Medium & 4,723 & 0.487 & 0.500 & Survey \\
Education: High & 4,723 & 0.177 & 0.381 & Survey \\
Female & 4,723 & 0.387 & 0.487 & Survey \\
UE in Prev 10 Yrs (Yes/No) & 4,723 & 0.712 & 0.453 & Admin \\
Work Experience > Median & 4,723 & 0.566 & 0.496 & Admin \\
& & & & \\
PBD in Months & 4,723 & 11.318 & 2.269 & Own calculation \\
UI Benefits (ALG I) & 4,723 & 819.803 & 242.820 & Admin \\
Welfare Benefits (ALG II) & 4,723 & 631 & 0 & Own calculation \\
\hline
\end{tabular}

Source: IZA Evaluation Dataset (survey) \& IAB Employment Biographies (admin). An exit from unemployment is defined as the transition to a job which is exceeds welfare benefits (631 euros per month) and lasts more than one month. Right-censoring applies if individuals are unemployed for more than 20 months. Wages are reported in monthly terms. "Education: Medium" takes the value one if the individual has finished the German Realschule or Fachoberschule. "Education: High" takes the value one if the individual holds the German Abitur. Prior unemployment and work experience both refer to the 10 years prior to entry into the current unemployment spell. The median work experience level over this period is 5 years. PBD is a function of the number of months worked during the 5 years prior to unemployment, and of age. UI benefits are a function of the pre-unemployment wage and of the number of children. Welfare benefits are means-tested and contain a payment for rent expenses and a payment for other living expenses. In practice, welfare benefits vary with household size. For simplification, we use here the average payment for a single individual. 
Table 2: Parameter Estimates

\begin{tabular}{lcc}
\hline & Estimate & S.E. \\
\hline Wage Offers & & \\
$\mu_{0}:$ & & \\
$\quad$ Constant & 3.008 & 0.037 \\
Log Pre-UE Wage & 0.599 & 0.005 \\
Education: Medium & 0.023 & 0.007 \\
Education: High & 0.178 & 0.008 \\
Female & -0.101 & 0.006 \\
Work Experience > Median & -0.012 & 0.006 \\
UE in Prev. 10 Yrs (Yes/No) & -0.001 & 0.006 \\
$\theta^{o b j}$ & 0.012 & 0.001 \\
$\theta^{s u b}$ & 0.001 & 0.002 \\
$\alpha^{s u b}$ & 0.073 & 0.021
\end{tabular}

\section{Inverse Elasticity of Search}

$\gamma$

$3.401 \quad 0.494$

\section{Search Costs}

$e_{0}$ :

Constant

$3.836 \quad 0.840$

Log Pre-UE Wage

$0.696 \quad 0.212$

Education: Medium

$-0.102 \quad 0.157$

Education: High

$0.251 \quad 0.208$

Female

$0.353 \quad 0.173$

Work Experience $>$ Median

$-0.179 \quad 0.152$

UE in Prev. 10 Yrs (Yes/No)

$-0.124 \quad 0.151$

$\theta^{e}$

$0.369 \quad 0.053$

\section{Variance Parameters}

SD of Log Wage Offers $\sigma_{w} \quad 0.305 \quad 0.003$

$\begin{array}{lll}\mathrm{SD} \text { of Log Wage Expectations } \sigma_{\epsilon} & 0.245 & 0.001\end{array}$

\begin{tabular}{lc}
\hline Average $\log \mathrm{L}$ & -2.678 \\
$\mathrm{~N}$ & 4,723 \\
\hline
\end{tabular}

Estimates are based on the likelihood specified by equations 9 and 10. The discount rate is set to $r=$ 0.0153. "Education: Medium" takes the value one if the individual has finished the German Realschule or Fachoberschule. "Education: High" takes the value one if the individual holds the German Abitur. Prior work and unemployment experience both refer to the 10 years prior to entry into the current unemployment spell. The median work experience level over this period is 5 years. 
Table 3: Simulated Average Effects of Information Provision and Search Cost Reduction

\begin{tabular}{lcccccc}
\hline & \multicolumn{2}{c}{ Information Provision } & & \multicolumn{2}{c}{ Search Cost Reduction } \\
\cline { 2 - 3 } \cline { 5 - 6 } \cline { 5 - 6 } & Simulated Effect & \% Change & & Simulated Effect & \% Change \\
\hline Duration of UE in Months & -0.7 & $-6.5 \%$ & & -0.2 & $-1.7 \%$ \\
UI Benefit Payment in Euros & -452.8 & $-5.9 \%$ & & -118.9 & $-1.5 \%$ \\
Monthly Gross Wage in Euros & 12.2 & $0.7 \%$ & & 1.6 & $0.1 \%$ \\
\hline
\end{tabular}

The counter-factual simulations are based on 1,000 random independent draws for each of the 4,723 individuals in the sample. The information provision imposes perfect information about wage offers by setting $\alpha^{s u b}=0$ and $\theta^{s u b}=\theta^{o b j}$. The search cost reduction decreases $e_{t}$ by $10 \%$ at each month of the spell.

Table 4: Simulated Average Effects of Information Provision, for Different Discount Factors

\begin{tabular}{|c|c|c|c|c|c|c|}
\hline & \multicolumn{2}{|c|}{$\mathrm{r}=1 \%$} & \multicolumn{2}{|c|}{$\mathrm{r}=1.53 \%$ (Baseline) } & \multicolumn{2}{|c|}{$\mathrm{r}=2 \%$} \\
\hline & Effect & $\%$ Change & Effect & $\%$ Change & Effect & $\%$ Change \\
\hline Duration of UE in Months & -1.1 & $-10.3 \%$ & -0.7 & $-6.5 \%$ & -0.5 & $-4.8 \%$ \\
\hline UI Benefit Payment in Euros & -728.7 & $-9.5 \%$ & -452.8 & $-5.9 \%$ & -334.3 & $-4.3 \%$ \\
\hline Monthly Gross Wage in Euros & 14.5 & $0.8 \%$ & 12.1 & $0.7 \%$ & 10.4 & $0.6 \%$ \\
\hline
\end{tabular}

The counter-factual simulations are based on 1,000 random independent draws for each of the 4,723 individuals in the sample. The information provision imposes perfect information about wage offers by setting $\alpha^{s u b}=0$ and $\theta^{s u b}=\theta^{o b j}$. The search cost reduction decreases $e_{t}$ by $10 \%$ at each month of the spell. 


\section{Appendix}

\section{A Gross-Net Conversion}

To convert gross re-employment wages into net terms, we exploit two main sources: (i) the theoretical tax schedule for 2008 and (ii) the fact that we observe pre-unemployment wages both in gross terms (administrative data) and in net terms (survey data).

We use a functional form similar to the ones by Heathcote et al. (2014) and Blundell et al. (2016) to approximate the theoretical relationship between gross pre-unemployment wages pre $_{i}$ and net pre-unemployment wages $\tau(\text { pre })_{i}$ :

$$
\widehat{\tau(p r e)}_{i}=\hat{\beta}^{*} \operatorname{pre}_{i}^{1-\mu}
$$

where $1-\mu$ describes the curvature of the tax function, i.e., its progressivity. We proceed in two steps. We first obtain $\mu=0.16$ from the theoretical schedule governing the income taxation of a single individual in 2008. We then relate net to gross pre-unemployment wages using equation 18. The function fits the data remarkably well, with an $R^{2}$ of 0.97. Figure A.1a presents the relationship between pre $_{i}$ and $\widehat{\tau(\text { pre })_{i}}$, and figure A.1b the relationship between the predicted $\widehat{\tau(p r e)_{i}}$ and the $\tau(\text { pre })_{i}$ observed in the survey data. We interpret the $\%$-deviation of $\tau(\text { pre })_{i}$ from $\widehat{\tau(p r e)}_{i}$ as a result of taxation rules applying to the individual's situation (e.g., marriage and family status etc.): $D e v_{i}=\frac{\tau(\text { pre })_{i}-\widehat{\tau(p r e)_{i}}}{\widehat{\tau(p r e)_{i}}}$.

We assume that the individual-specific rules still apply after the unemployment spell, and measure individual $i$ 's net re-employment wage $\tau(w)_{i}$ as:

$$
\tau(w)_{i}=\widehat{\tau(w)_{i}}+\operatorname{Dev}_{i} \times \widehat{\tau(w)_{i}}
$$

where $\widehat{\tau(w)_{i}}=\hat{\beta}^{*} w_{i}^{1-\mu}$ is the theoretical net gross re-employment wage, with $\hat{\beta}$ estimated from equation 18 .

Figure A.1: Pre-Unemployment Wages: Gross, Predicted Net and Net

(a) Gross and Predicted Net Pre-UE Wages

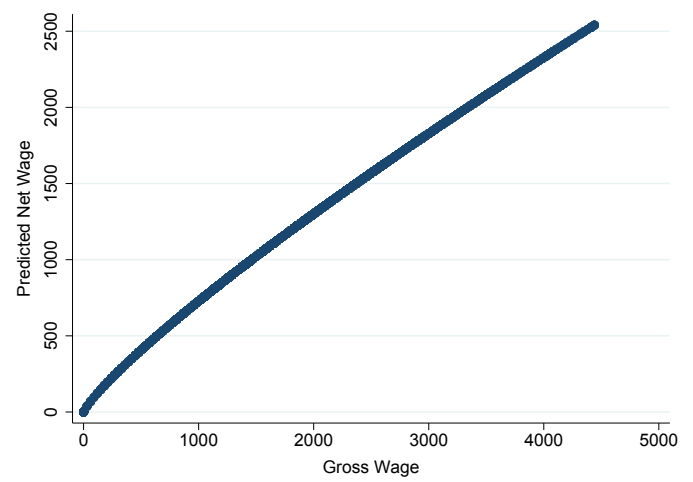

(b) Predicted Net and Net Pre-UE Wages

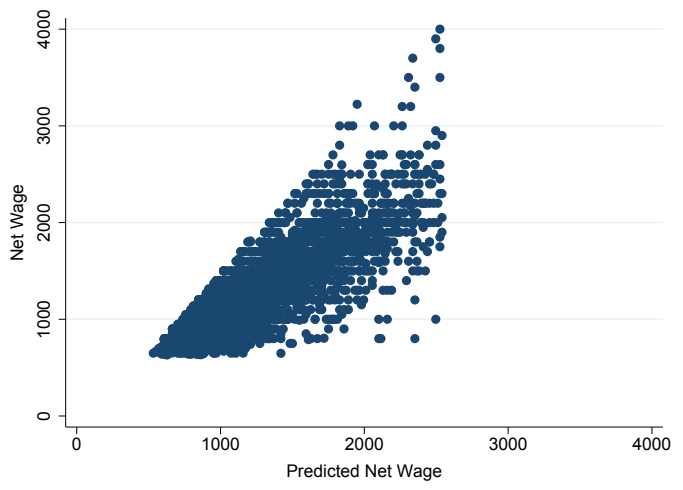




\section{B Additional Descriptive Evidence}

Figure A.2: Re-Employment Log Wage (Net)

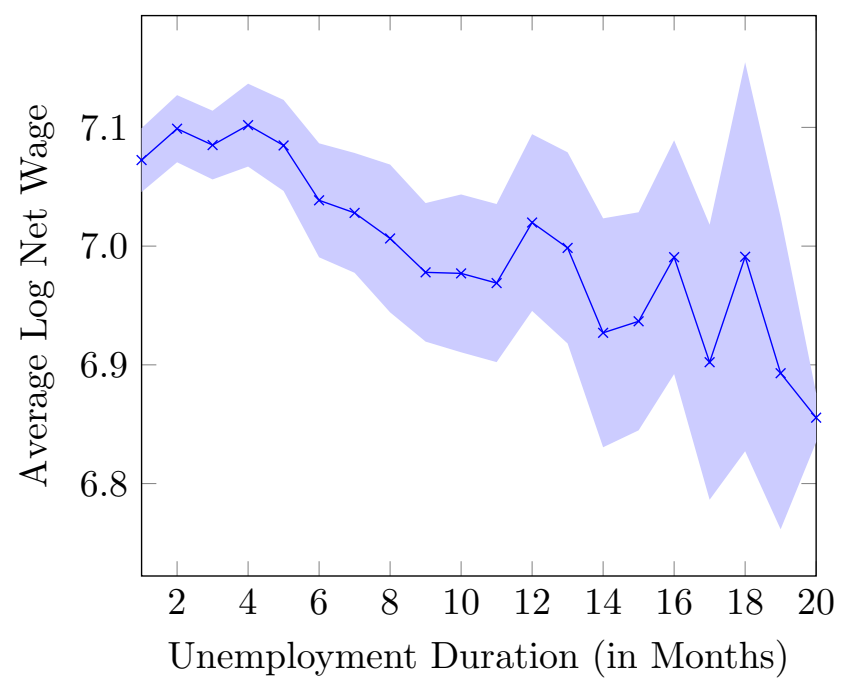

Source: IAB Employment Biographies. Gross wages are converted into net terms according to the procedure described in appendix A. The shaded area shows 95\% confidence bands. The graph includes individuals who enter re-employment within 20 months $(\mathrm{N}=3,642)$.

Figure A.3: Deciles of Re-Employment Log Wage (Net)

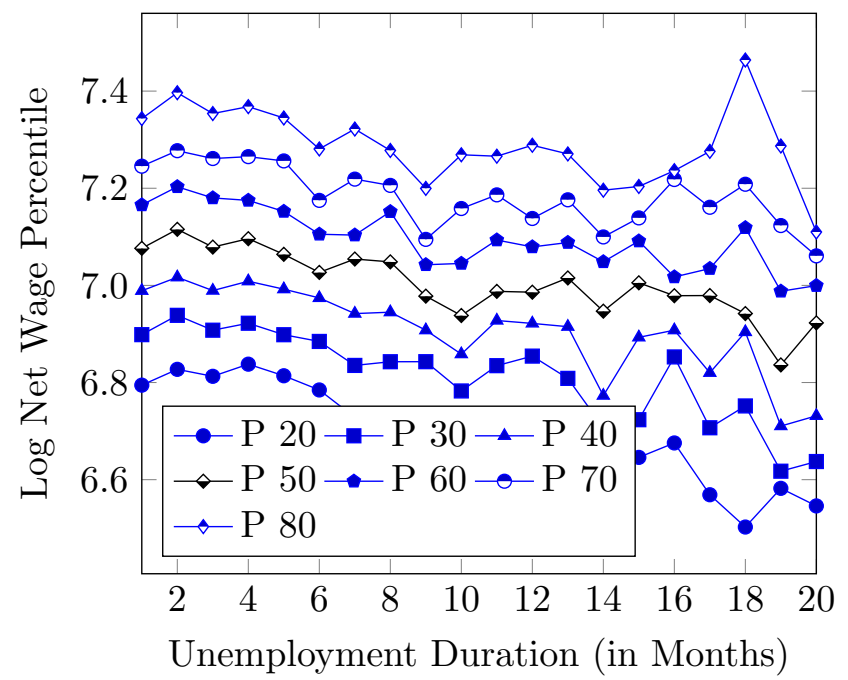

Source: IAB Employment Biographies. Gross wages are converted into net terms according to the procedure described in appendix A. The graph includes individuals who enter re-employment within 20 months $(\mathrm{N}=3,642)$. 
Figure A.4: Re-Employment Minus Pre-Unemployment Log Wage (Net)

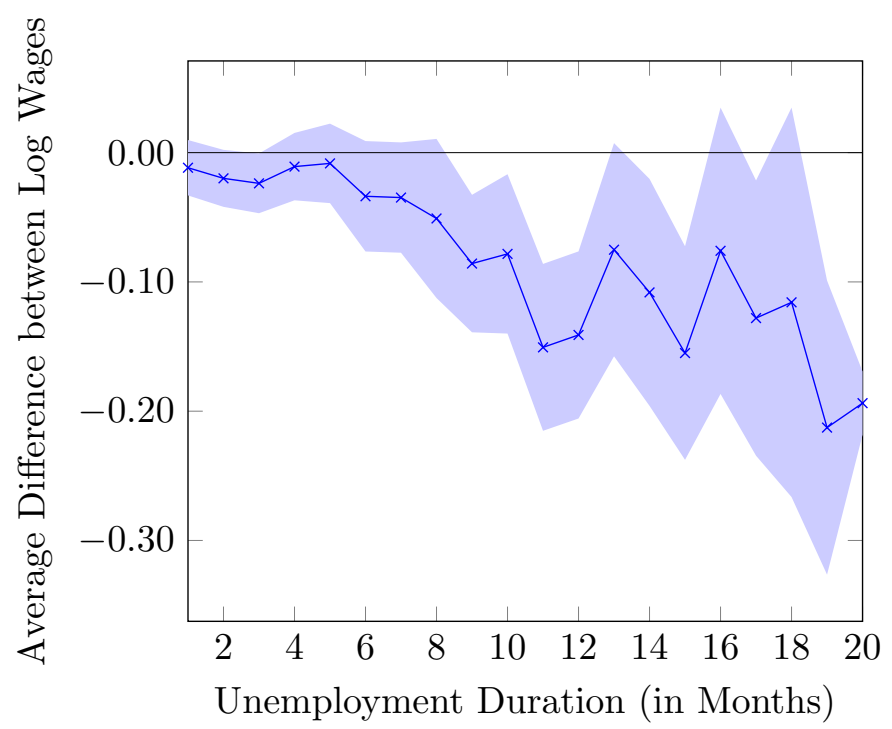

Source: IAB Employment Biographies. ross wages are converted into net terms according to the procedure described in appendix A. The shaded area shows $95 \%$ confidence bands. The graph includes individuals who enter re-employment within 20 months $(\mathrm{N}=3,642)$.

Table A.1: Wage Optimism and Individual Characteristics

\begin{tabular}{lcc}
\hline & Ratio Re-Employment/Expected Wage & $\mathbb{1}($ Ratio $<$ Median $)$ \\
& $(1)$ & $(2)$ \\
\hline Log Pre-UE Wage & $-0.065^{* * *}$ & 0.023 \\
Female & $(0.015)$ & $(0.028)$ \\
& -0.014 & 0.022 \\
Education: Medium & $(0.010)$ & $(0.020)$ \\
& $0.017^{*}$ & -0.033 \\
Education: High & $(0.010)$ & $(0.021)$ \\
& $0.039^{* *}$ & $-0.067^{* *}$ \\
Work Experience $>$ Median & $(0.015)$ & $(0.029)$ \\
& $0.036^{* * *}$ & $-0.038^{*}$ \\
UE in Prev. 10 Yrs (Yes/No) & $(0.011)$ & $(0.020)$ \\
& $0.025^{* *}$ & $-0.061^{* * *}$ \\
& $(0.011)$ & $(0.022)$ \\
\hline Outcome Mean & 0.906 & 0.476 \\
& 2874 & 2874 \\
\hline
\end{tabular}

The sample includes individuals with an observed wage expectation, re-entering employment within the observation period (20 months). "Education: Medium" takes the value one if the individual has finished the German Realschule or Fachoberschule. "Education: High" takes the value one if the individual holds the German Abitur. Individuals in the baseline category hold a lower level of education. Prior unemployment and work experience both refer to the 10 years prior to entry into the current unemployment spell. The median work experience level over this period is 5 years. Robust standard errors. ${ }^{*} p<0.10,{ }^{* *} p<$ $0.05,{ }^{* * *} p<0.01$. 


\section{Additional Parameter Estimates}

Table A.2: Parameter Estimates: Lower Bound Discount Factor $(\mathrm{r}=0.01)$

\begin{tabular}{|c|c|c|}
\hline & Estimate & S.E. \\
\hline \multicolumn{3}{|l|}{ Wage Offers } \\
\hline \multicolumn{3}{|l|}{$\mu_{0}:$} \\
\hline Constant & 3.059 & 0.059 \\
\hline Log Pre-UE Wage & 0.592 & 0.008 \\
\hline Education: Medium & 0.027 & 0.007 \\
\hline Education: High & 0.184 & 0.008 \\
\hline Female & -0.099 & 0.006 \\
\hline Work Experience $>$ Median & -0.011 & 0.007 \\
\hline UE in Prev. 10 Yrs (Yes/No) & -0.002 & 0.006 \\
\hline$\theta^{o b j}$ & 0.012 & 0.001 \\
\hline$\theta^{s u b}$ & 0.000 & 0.002 \\
\hline$\alpha^{s u b}$ & 0.063 & 0.020 \\
\hline \multicolumn{3}{|l|}{ Inverse Elasticity of Search } \\
\hline$\gamma$ & 3.319 & 1.042 \\
\hline \multicolumn{3}{|l|}{ Search Costs } \\
\hline \multicolumn{3}{|l|}{$e_{0}:$} \\
\hline Constant & 3.840 & 1.975 \\
\hline Log Pre-UE Wage & 0.690 & 0.216 \\
\hline Education: Medium & -0.093 & 0.162 \\
\hline Education: High & 0.255 & 0.212 \\
\hline Female & 0.396 & 0.218 \\
\hline Work Experience > Median & -0.181 & 0.155 \\
\hline UE in Prev. 10 Yrs (Yes/No) & -0.143 & 0.156 \\
\hline$\theta^{e}$ & 0.367 & 0.107 \\
\hline \multicolumn{3}{|l|}{ Variance Parameters } \\
\hline SD of Log Wage Offers $\sigma_{w}$ & 0.305 & 0.003 \\
\hline SD of Log Wage Expectations $\sigma_{\epsilon}$ & 0.246 & 0.001 \\
\hline Average $\log \mathrm{L}$ & \multicolumn{2}{|c|}{-2.677} \\
\hline $\mathrm{N}$ & \multicolumn{2}{|c|}{4,723} \\
\hline
\end{tabular}

Estimates are based on the likelihood specified by equations 9 and 10. "Education: Medium" takes the value one if the individual has finished the German Realschule or Fachoberschule. "Education: High" takes the value one if the individual holds the German Abitur. Prior work and unemployment experience both refer to the 10 years prior to entry into the current unemployment spell. The median work experience level over this period is 5 years. 
Table A.3: Parameter Estimates: Upper Bound Discount Factor $(\mathrm{r}=0.02)$

\begin{tabular}{lcc}
\hline & Estimate & S.E. \\
\hline Wage Offers & & \\
$\mu_{0}:$ & & \\
$\quad$ Constant & 2.991 & 0.035 \\
Log Pre-UE Wage & 0.601 & 0.005 \\
Education: Medium & 0.025 & 0.007 \\
Education: High & 0.183 & 0.008 \\
Female & -0.097 & 0.006 \\
Work Experience > Median & -0.012 & 0.006 \\
UE in Prev. 10 Yrs (Yes/No) & -0.003 & 0.006 \\
$\theta^{\text {obj }}$ & 0.012 & 0.001 \\
$\theta^{\text {sub }}$ & 0.001 & 0.002 \\
$\alpha^{\text {sub }}$ & 0.079 & 0.021
\end{tabular}

\section{Inverse Elasticity of Search}

$3.446 \quad 0.561$

\section{Search Costs}

$e_{0}$ :

Constant

$3.834 \quad 0.687$

Log Pre-UE Wage

$0.690 \quad 0.206$

Education: Medium

$-0.106 \quad 0.157$

Education: High

$0.248 \quad 0.204$

Female

$0.338 \quad 0.171$

Work Experience $>$ Median

$-0.177 \quad 0.149$

UE in Prev. 10 Yrs (Yes/No)

$-0.118 \quad 0.149$

$\theta^{e}$

$0.368 \quad 0.058$

\section{Variance Parameters}

SD of Log Wage Offers $\sigma_{w} \quad 0.306 \quad 0.003$

SD of Log Wage Expectations $\sigma_{\epsilon} \quad 0.246 \quad 0.001$

\begin{tabular}{lc}
\hline Average Log L & -2.678 \\
$\mathrm{~N}$ & 4,723 \\
\hline
\end{tabular}

Estimates are based on the likelihood specified by equations 9 and 10. "Education: Medium" takes the value one if the individual has finished the German Realschule or Fachoberschule. "Education: High" takes the value one if the individual holds the German Abitur. Prior work and unemployment experience both refer to the 10 years prior to entry into the current unemployment spell. The median work experience level over this period is 5 years. 